\title{
Os diversos "Pedros" que habitam as cidades: violência, cotidiano e experiência urbana em Contos de Pedro e Passageiro do fim do dia, de Rubens Figueiredo
}

\section{Carolina Montebelo Barcelos ${ }^{1}$}

\begin{abstract}
Resumo: Pedro é nome de personagens em diversas obras da literatura brasileira, como Capitães de Areia, de Jorge Amado, e Lira Paulistana, de Mário de Andrade. Em comum, esses Pedros têm a origem em uma classe social pobre e trabalhadora. $O$ professor, tradutor e escritor Rubens Figueiredo também dedicou boa parte de sua obra ficcional à retratação do cotidiano das vítimas da injustiça e exclusão social, principalmente nas áreas urbanas e suas periferias. Portanto, o objetivo deste artigo é examinar os modos pelos quais a violência, seja ela de caráter físico ou oriunda da desigualdade social, é representada em Contos de Pedro, de 2006, e Passageiro do fim do dia, publicado em 2010. Críticos e teóricos como Beatriz Resende e Karl Erik Schollhammer veem uma heterogeneidade na literatura brasileira contemporânea e, dentre suas diversas características, a urgência em se relacionar com a realidade histórica pode ser percebida nos contos e romance analisados aqui, haja vista a necessidade que Rubens Figueiredo mostra ao abordar a realidade social e urbana.Seja através da perspectiva do Pedro de Passageiro do fim do dia, ou do olhar onisciente dos narradores dos Contos de Pedro, estamos diante de jovens e adultos, mulheres e homens,cuja exclusão social pode ser percebida por meio de temas como solidão, educação e escola, violência e desilusão. É através do cotidiano de vida e trabalho precários dos Pedros dos contos, ou da perspectiva experienciada por Pedro no romance, que o autor, tal como Chico Buarque na música Pedro Pedreiro, denuncia a opressão da classe trabalhadora brasileira.
\end{abstract}

Palavras-chave: Literatura brasileira; Violência, Experiência urbana; Rubens Figueiredo.

Los diversos "Pedros"que habitan las ciudades: violencia, cotidiano y experiencia urbana en Contos de Pedro e Passageiro do fim do dia, de Rubens Figueiredo

Resumen: Pedro es el nombre de los personajes de varias obras de la literatur abrasilera, como Capitães de Areia, de Jorge Amado, y Lira Paulistana, de Mário de Andrade. En común, estos Pedros se originan de una clase social pobre y trabajadora. El profesor, traductor y escritor Rubens Figueiredo también dedicó gran parte de sus ficciones a retratar la vida cotidiana de las víctimas de la injusticia y la exclusión social, especialmente en las zonas urbanas y sus periferias. Por lo tanto, el objetivo de este artículo es examinar las formas en que la violencia, ya sea física o social, está representada en Contos de Pedro, 2006, y Passageiros do fim do dia, publicado en 2010. Críticos y teóricos como Beatriz Resende y Karl Erik Schollhammer ven una heterogeneidad en la literatura brasilera contemporánea $\mathrm{y}$, entre sus varias características, la urgencia de relacionarse con la realidad histórica se puede percibir en los cuentos y novela analizados aquí, dada la necesidad que Rubens Figueiredo muestra al abordar la realidad social y urbana. Ya sea a través de la perspectiva de Pedro de Passageiro do fim do dia, o la mirada omnisciente del narrador de Contos de Pedro, estamos delante de jóvenes y adultos, mujeres y hombres, cuya exclusión social se puede percibir a través de temas como la soledad, la educación y la escuela, violencia y desilusión. Es a través de la

\footnotetext{
${ }^{1}$ Carolina Montebelo Barcelos Doutora em Literatura, Cultura e Contemporaneidade, pela PUC-Rio, Brasil. E-mail: carolinambarcelos@hotmail.com - http://orcid.org/0000-0002-2644-0704
} 
precaria vida cotidiana y el trabajo de Pedros dos cuentos, o la perspectiva que Pedro experimentó, en la novela, que el autor, como Chico Buarque en la canción Pedro Pedreiro, denuncia la opresión de la clase trabajadora brasilera.

Palabras clave: Literatura brasilera; Violencia; Experiencia urbana; Rubens Figueiredo.

The several "Pedros" who inhabit the cities: violence, everyday life and urban experience in Rubens Figueiredo's Contos de Pedro e Passageiro do fim do dia

\begin{abstract}
Pedro is the name of characters in several works of Brazilian Literature, such as Capitães de Areia, by Jorge Amado, andLira Paulistana, by Mário de Andrade. What they have in common is that these Pedros originate from the poor working class. The teacher, translator and writer Rubens Figueiredo also committed part of his fictional works to the portrayal of the everyday life of the victims of injustice and social exclusion, especially in urban areas and their outskirts. Thus, the aim of this article is to examine the ways in which violence, be it physical or deriving from social inequality, is represented in Contos de Pedro, from 2006, andPassageiro do fim do dia, published in 2010. Critics and scholarssuch as Beatriz Resende and Karl Erik Schollhammer see a heterogeneity in contemporary Brazilian Literature and, amongst its diverse characteristics, the urgency in relating to the historic reality can be noticed in the short stories and novel analyzed here, given the need Rubens Figueiredo shows when approaching the social and urban reality. Whether it be from Pedro'sPassageiro do fim do diaperspective or from the omniscient views ofContos de Pedro's narrator, we are before young and adults, women and men whose social exclusion can be perceived by means of themes such as loneliness, education and school, violence and disillusionment. It is through everyday life and the precarious jobs of the Pedros in the short stories or from the perspective experienced by Pedro in the novel that the author, just as Chico Buarque did in the song Pedro Pedreiro, reports the oppression of the Brazilian working class.
\end{abstract}

Keywords: Brazilian literature; Violence; Urban experience; Rubens Figueiredo.

\title{
Os diversos "Pedros" que habitam as cidades:violência, cotidiano e experiência urbana em Contos de Pedro e Passageiro do fim do dia, de Rubens Figueiredo
}

No meio do caminho tinha uma pedra tinha uma pedra no meio do caminho tinha uma pedra no meio do caminho tinha uma pedra.

Nunca me esquecerei desse acontecimento na vida de minhas retinas tão fatigadas.

Nunca me esquecerei que no meio do caminho tinha uma pedra tinha uma pedra no meio do caminho no meio do caminho tinha uma pedra.

Carlos Drummond e Andrade, No meio do caminho, 1928.

\section{Introdução}

Pedra, elemento rígido, fragmento de rocha. No poema de Drummond, a pedra surge repetidamente no caminho como obstáculo a ser superado cotidianamente, o que é reforçado pela repetição - "no meio do caminho tinha uma pedra" - presente no poema. 
Pedro, nome que vem de pedra, nome aparentemente comum, tem sido personagem de diversas obras da literatura brasileira. Em algumas delas, Pedro faz parte de um estrato social desprivilegiado do Brasil, aquele para quem há sempre muitas pedras no caminho. Assim, temos Pedro Bala, em Capitães de Areia, de Jorge Amado, e o personagem folclórico Pedro Malasartes, herança dos contos populares da Península Ibérica, que inspirou filmes, teatro, circo e óperas, além da sua semelhança com Macunaíma, de Mário de Andrade.

O Pedro da Lira Paulistana, também de Mário de Andrade, não tem a astúcia e galhardia de Pedro Malasartes ou de Macunaíma, nem a coragem e espírito de liderança do marginalizado Pedro Bala. Também não tem 0 elemento destruidor $\mathrm{e}$ exploratório de Venceslau Pietro Pietra - ou Pedro Pedra -,o gigante Piaimã, antagonista de Macunaíma. No poema, o Pedro marioandradino faz parte de uma classe social pobre, com uma trajetória de agruras desde 0 nascimento até a morte:

Uma história muito triste

Que nunca ninguém cantou, A triste história de Pedro, Que acabou qual principiou (ANDRADE, 1987).
Quando criança,

Pedrinho engatinhou logo

Mas muito tarde falou;

Ninguém falava com ele,

Quando chorava era surra

E aprendeu a emudecer

(ANDRADE, 1987).

Atrás do quarto alugado onde morava, ou atrás da escola onde estudara antes dos pais o tirarem de lá, havia uma serra que se tornara para ele um escapismo do árduo cotidiano:

- Havia de ter, decerto, Uma vida bem mais linda Por trás da serra, pensou (ANDRADE, 1987).

Na fase adulta, a vida de Pedro não melhoraria. Ele já não veria mais uma serra que se encontrava atrás da fábrica onde trabalhava. Sua vida de trabalhador pobre minou as ilusões metaforizadas pela imagem da serra que tinha quando mais novo. Ele era apenas mais um Pedro dentre muitos:

Por trás do túmulo dele

Tinha outro túmulo... Igual

(ANDRADE, 1987).

Assim também parece ser 0 cotidiano dos diversos Pedros narrados por Rubens Figueiredo em Contos de Pedro (nas nove histórias, o protagonista se chama Pedro) e no romance Passageiro do fim do dia. $\mathrm{Na}$ 
BARCELOS, Carolina Montebelo. Os diversos "Pedros" que habitam as cidades: violência e experiência urbana em "Contos de Pedro" e

"Passageiro do fim do dia", de Rubens Figueiredo. PragMATIZES

Revista Latino-Americana de Estudos em Cultura, Niterói/RJ, Ano 10, n 18, p. 140-154, out. 2019 a março 2020.

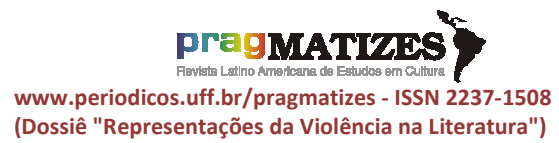

(Dossiê "Representações da Violência na Literatura") maioria dos contos e no romance, o autor procura representar um cotidiano da classe pobre trabalhadora, jovens e adultos, mulheres e homens, onde exclusão social, violência e solidão delineiam situações e personagens. Dessa forma, procura-se, neste estudo, examinar os modos pelos quais a violência, seja ela de caráter físico ou oriunda da desigualdade social, é representada em Contos de Pedro, de 2006, e Passageiro do fim do dia, publicado em 2010.

Professor de Português, romancista, contista e tradutor, Rubens Figueiredo já foi premiado pelos livros Barco a seco e Palavras secretas. Passageiro do fim do dia foi contemplado, em agosto de 2011, como o melhor livro do ano pelo Prêmio São Paulo de Literatura, e, em dezembro daquele mesmo ano, pelo Prêmio Portugal Telecom de Literatura. Seus textos têm figurado em alguns artigos sobre literatura contemporânea, em coletâneas como Geração 90: manuscritos de computador, organizado por Nelson de Oliveira, e Rio literário: um guia apaixonado da cidade do Rio de Janeiro, organizado por Beatriz Resende, e receberam fortuna crítica aprofundada por Paulo Roberto Tonani do Patrocínio em Os (não) adaptados: a experiência urbana na obra de Rubens Figueiredo (RESENDE, 2014), Passageiro do fim do dia, de Rubens Figueiredo: um olhar sobre 0 naturalismo (CHIARELLI; DEALTRY; VIDAL, 2013) e Cidade de lobos: a representação de territórios marginais na obra de Rubens Figueiredo (PATROCÍNIO, 2016).

Críticos e teóricos da literatura tais como Beatriz Resende (2008) e Karl Erik Schollhammer (2009) acreditam que a literatura brasileira contemporânea se caracteriza por uma pluraridade de formas e temas e identificam traços marcantes como narrativas curtas, estruturas fragmentadas, urgência em se relacionar com a realidade histórica, insistência do presente temporal, presentificação do autor, hibridismos entre a escrita literária e não-literária e utilização e tecnologias como internet e blogs. Alguns desses traços podem ser percebidos na escrita de Rubens Figueiredo, principalmente a necessidade que o autor mostra em se relacionar com a realidade social e urbana. 
BARCELOS, Carolina Montebelo. Os diversos "Pedros" que habitam as cidades: violência e experiência urbana em "Contos de Pedro" e

"Passageiro do fim do dia", de Rubens Figueiredo. PragMATIZES

Revista Latino-Americana de Estudos em Cultura, Niterói/RJ, Ano 10, n. 18, p. 140-154, out. 2019 a março 2020.

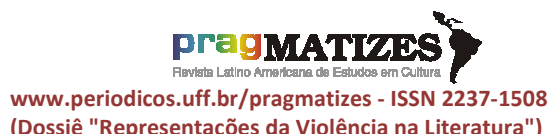

(Dossiê "Representações da Violência na Literatura")
Karl Erik Schollhammer (2009) percebe nos escritores mais recentes uma busca pela reinvenção de formas históricas do realismo ao lidarem com questões como crime, violência, corrupção e miséria. Um traço comum a esses escritores seria, segundo Schollhammer, a demanda de presença que, contudo, se apresenta de forma variada:

para alguns - Marcelino Freire, Luiz Ruffato, Marçal Aquino, Nelson de Oliveira, Fernando Bonassi, entre outros -, se evidencia na perspectiva de uma invenção do realismo, à procura de um impacto numa determinada realidade social, ou na busca de se refazer a relação de responsabilidade e solidariedade com os problemas sociais e culturais de seu tempo. Para outros - Rubens Figueiredo, Adriana Lisboa, Michel Laub e João Anzanello Carrascoza- , evocar e lidar com a presença tornase sinônimo de consciência subjetiva e de uma aproximação literária ao mais cotidiano, autobiográfico e banal, o estofo material da vida ordinária em seus detalhes mínimos (SCHOLLHAMMER, 2009, p. 15).

No entanto, o crítico não vê uma polarização entre essas duas vertentes, ao postular que "A literatura que hoje trata dos problemas sociais não exclui a dimensão pessoal e íntima, privilegiando apenas a realidade exterior; o escritor que opta por ressaltar a experiência subjetiva não ignora a turbulência do contexto social e histórico" (SCHOLLHAMMER,
2009, p. 15). Dessa forma, Contos de Pedro e Passageiro do fim do dia tratam da vida ordinária e do cotidiano dos diversos Pedros, mas fazendo da realidade social e dos problemas que dela derivam a tônica das narrativas. Como afirma Beatriz Resende (2002),

Numa sociedade em que talvez
apenas Luiz Ruffato e Rubens
Figueiredo, dentre os
contemporaníssimos, lançam mão de
um olhar onde haja marcas políticas,
o individualismo agrava a certeza da
impossibilidade das relações
humanas a cidade é sobretudo
ameaça, mesmo quando olhada do
alto da janela que provoca (várias
vezes) desejos de um salto no
espaço.

Dos nove contos, em apenas um o protagonista narra sua própria história, mas tanto a narrativa de Passageiro do fim do dia quanto as histórias de Contos de Pedro não possuem uma linearidade, são cheias de idas e vindas cronológicas, de flashbacks.Em Passageiro do fim do dia, vemos uma narrativa que, a princípio, poderia nos remeter a fluxos de consciência, pois não é linear, faz associação de ideias, promove rupturas e mostra lembranças entremeadas pelo presente concreto. Entretanto, talvez fosse melhor pensar a estrutura narrativa do romance como fluxos de fragmentos de memória: 
Pedro de lembra de algo, esse algo é associado a alguma outra lembrança, ele retorna à leitura, comenta sobre passageiros, cria história de vida para eles e sobre que está prestes a acontecer, volta à leitura, às lembranças e ao presente em que se narra. O mesmo acontece em Contos de Pedro quando, por exemplo, toda a angústia e temor do Pedro de "O nome que falta", no momento em que imagina que está prestes a ser baleado, é entrecortada por memórias do personagem de várias pessoas que se esconderam de um tiroteio, que foram baleadas e até mesmo assassinadas. A narrativa do momento em que 0 ponto vermelho, provavelmente uma mira de fuzil, se volta para sua cabeça, é também cortada para mostrar como Pedro entendia a mensagem que o cachorro queria the passar sobre esse momento.

Nenhuma das narrativas trata da enunciação pedestre proposta por Michel de Certeau, da visão panorâmica ou do observador da janela. $O$ que o passageiro Pedro, do romance, vê da janela, é apenas ônibus que emparelham para avisar que o motorista não deva prosseguir a viagem. Entretanto, a assertiva de Certeau de que "a cidade é um espaço de guerra de relatos: pequenos discursos cotidianos de um instante" (CERTEAU, 2009, p. 30) vale para toda a escrita de Rubens Figueiredo examinada aqui.

Violência, cotidiano e experiência urbana em Contos de Pedro e Passageiro do fim do dia

A maior parte da narrativa de Passageiro do fim do dia se dá dentro do ônibus que Pedro pega para ir do centro da cidade até o bairro de Tirol, região periférica onde fica a casa de Rosane, sua namorada, e onde ele passa finais de semana. Nessa viagem, que parece fazer parte do cotidiano dos passageiros, Pedro opera fluxos de memória de fatos de sua vida pessoal e de suas experiências no Tirol, entremeados com observações sobre os passageiros do ônibus e sobre o que vê da janela durante todo o trajeto.

Segundo Rubens Figueiredo, a ideia do livro surgiu a partir de sua experiência pessoal, uma vez que sempre andou muito de ônibus. No entanto, o escritor também afirma "embora seja pessoal na origem, ela 
BARCELOS, Carolina Montebelo. Os diversos "Pedros" que habitam as cidades: violência e experiência urbana em "Contos de Pedro" e

"Passageiro do fim do dia", de Rubens Figueiredo. PragMATIZES

Revista Latino-Americana de Estudos em Cultura, Niterói/RJ, Ano 10, n. 18, p. 140-154, out. 2019 a março 2020.

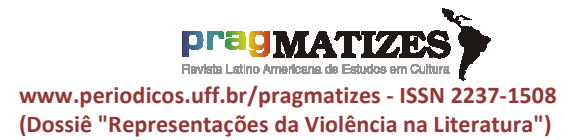

No romance, não é exatamente Pedro a maior vítima da desigualdade social e, sim, sua namorada Rosane, seus familiares e vizinhos. Rosane, por exemplo, havia trabalhado em uma fábrica de copo de refresco e, ao ser demitida após algumas faltas por conta de um problema no pulso adquirido em função do trabalho que exercia, teve touca, chinelo, uniforme e atrasos descontados. Ironicamente, essa mesma fábrica patrocinava uma campanha de preservação de um tipo de ave marinha que vivia em uma ilha deserta. (FIGUEIREDO, 2010, p. 158). Pedro, por seu turno, age como o mediador entre o centro e a periferia. Ele não é do Tirol e, por vezes,pensa que os outros passageiros estão piores que ele, pois ele não necessariamente precisa estar lá. Sua distância do Tirol é tanto física e geográfica quanto social.

Já nos contos, embora haja uma heterogeneidade social dos personagens, a maioria dos Pedros ou é vítima direta da desigualdade social ou é protagonista de uma história onde esta questão é premente. Em "O dente de ouro", Pedro é porteiro e faxineiro, cobre horas de outros funcionários, dorme em um quarto minúsculo, cuja 
janela é voltada para a garagem do prédio e, depois de empréstimos concedidos e não devidamente pagos, além do exíguo salário que recebia, foi demitido, mas, com os descontos, nada recebeu. No entanto, para os moradores do prédio, não importava o quanto o faxineiro e porteiro tivesse trabalhado, "ser submisso não bastava. Exigiam-se repetidas derrotas cotidianas." (FIGUEIREDO, 2006, p. 11).

Dessa forma, a violência está sempre na escrita de Figueiredo nos textos aqui analisados, em várias camadas, menos na criminalidade, tão em pauta na literatura contemporânea, e mais na opressão e desigualdade social. A criminalidade não está no foco do romance ou contos, embora em um ou outro momento do romance ou de alguns contos ela apareça vitimando alguns personagens. Muitas vezes a desigualdade social é mostrada de modo irônico, como o fato de, no romance, o ônibus em que Pedro se encontra poder estar prestes a ser incendiado, enquanto lembra-se que em um dia de trabalho em um sebo, um homem folheava com encantamento um livro sobre instalação com automóveis batidos ou incendiados (FIGUEIREDO, 2010, p. 144).

O livro e a escola são presenças constantes no romance: a escola que Rosana pretende concluir, o livro do sebo (sobre passarinhos e discos-voadores) que leva para o guarda-vida, amigo da família de Rosane, o livro de inglês que dá para Rosane estudar, o livro que a juíza folheia sobre a instalação de automóveis e, principalmente, o livro sobre Darwin que Pedro lê. Segundo Rubens Figueiredo, a escolha sobre Darwin estava relacionada à tônica de seu romance:

Havia mais um motivo pelo qual
considerei interessante incluir
Darwin, era a questão da ciência.
Como a ciência e a literatura podiam
servir de instrumentos para aquele
mesmo processo de dominação e de
justificação da desigualdade [...]. Ou
como a teoria da evolução poderia
servir para justificar a desigualdade,
deixando de ser uma questão
científica para ser uma questão
social (COUTINHO, 2011, p. 2).

Em todos os contos a escola também se faz presente e ela é também marca da denúncia do escritor da desigualdade social. Em "De forno a forno", a escola que o jovem Pedro frequentava, já dando claros sinais de descaso do tempo, foi "construída muitos anos antes para abrigar uma 
BARCELOS, Carolina Montebelo. Os diversos "Pedros" que habitam as cidades: violência e experiência urbana em "Contos de Pedro" e

"Passageiro do fim do dia", de Rubens Figueiredo. PragMATIZES

Revista Latino-Americana de Estudos em Cultura, Niterói/RJ, Ano 10, n 18, p. 140-154, out. 2019 a março 2020.

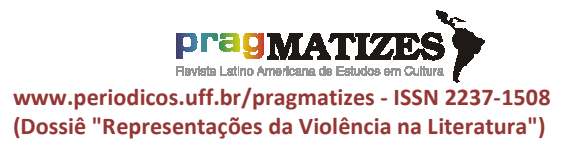

Quando Pedro voltou, horas depois, o homem não estava mais lá" (FIGUEIREDO, 2006, p. 45). Posteriormente, com a morte desse mendigo, logo viria outro: "exatamente no mesmo ponto, sobre a mesma mancha que já estava lá, como se fosse um lugar marcado: um outro homem, o novo rei da rua" (FIGUEIREDO, 2006, p. 48).

As marcas constantes de violência se encontram em todas as histórias contadas; são marcas nos corpos, cicatrizes que não deixam os personagens se esquecerem de seu duro cotidiano. Em Passageiro do fim do dia, o próprio Pedro teve a perna esmagada por um cavalo quando se viu no meio de um confronto entre policiais e ambulantes; João, que Pedro conheceu num hospital, foi atropelado por um caminhão, teve o corpo quase destruído e perdeu a memória; a cicatriz profunda da colega de escola de Rosane que foi atingida por uma bala perdida - de um assaltante de ônibus fugindo da polícia - de pistola atravessada no seu corpo em vários órgãos, quando ela estava grávida de seis meses; o pé do pai de Rosane, sacrificado pelo trabalho quando era pedreiro. No conto bordadas de rachaduras secas. 
BARCELOS, Carolina Montebelo. Os diversos "Pedros" que habitam as cidades: violência e experiência urbana em "Contos de Pedro" e

"Passageiro do fim do dia", de Rubens Figueiredo. PragMATIZES

Revista Latino-Americana de Estudos em Cultura, Niterói/RJ, Ano 10, n. 18, p. 140-154, out. 2019 a março 2020.

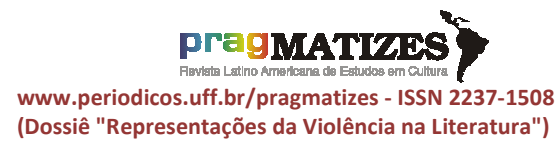

também seu filho, sua nora e dois netos. Apesar das dificuldades financeiras que a família do filho se encontra, este consegue construir um galinheiro para auxiliar na renda e um quarto junto à casa. Contudo, certo dia Pedro decide destruir a morada do filho: "abri a tampa da caixa de esgoto no chão do quintal, usei dois pedaços de madeira compensada como se fossem pás e empurrei lá para dentro toda a areia, a terra e a brita que estavam acumuladas num canto" (FIGUEIREDO, 2006, p. 48). Igualmente, Pedro também destrói 0 galinheiro: "[...] enfiei as mãos no galinheiro e estrangulei os pintos, um por um, só com quatro dedos da mão. Também torci o pescoço das galinhas, que vieram como loucas bicar meu braço" (FIGUEIREDO, 2006, p. 48). A destruição de todo o pouco que o filho, nora e netos tinham materializam a saída de casa dessa família e o consequente abandono que Pedro sofreria.

O Pedro de "Uma questão de lógica", ao forçar a saída do filho e família, aponta para um outro elemento presente nos demais contos: a solidão. Os Pedros, sejam do centro ou da periferia, encontram-se em uma 
BARCELOS, Carolina Montebelo. Os diversos "Pedros" que habitam as cidades: violência e experiência urbana em "Contos de Pedro" e

"Passageiro do fim do dia", de Rubens Figueiredo. PragMATIZES

Revista Latino-Americana de Estudos em Cultura, Niterói/RJ, Ano 10, n. 18, p. 140-154, out. 2019 a março 2020.

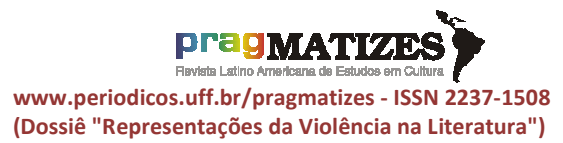

(Dossiê "Representações da Violência na Literatura") cidade populosa, mas sempre estão, de algum modo, sozinhos. Esse elemento é amplificado no último conto, "Céu negro", onde um homem, um pedreiro, beirando os setenta anos, se compraz com relações sexuais fugazes com mulheres muito mais jovens, em troca de presentes. Em uma dessas relações, Pedro vai à casa da mulher - ao contrário do costumeiro, pois são elas que vão a sua casa - na periferia, se defronta com a área inóspita e com a possibilidade de perder a vida quando o parceiro da mulher chega na casa dela.

Paulo Roberto Tonani do Patrocínio, ao examinar as diferentes escritas sobre os marginalizados, afirma que "a violência e o tráfico de drogas surgem, na contemporaneidade, como elementos quase indissociáveis da favela. Seja em textos jornalísticos ou em discursos oficiais, tais aspectos são examinados quase como sinônimos para favela. Torna-se, assim, quase impossível desagregar os termos violência e favela" (PATROCÍNIO, 2006). Esse tipo de violência, fruto da criminalidade retratada, por exemplo, por Paulo Lins em Cidade de Deus, não corresponde ao tratamento dado por Rubens Figueiredo no romance e nos contos aqui examinados. Embora o tráfico e o crime estejam presentes, não são sublinhados. Nesse sentido, o único conto em que a violência se mostra de forma mais crua é "O nome que falta". Aqui, o homem é sempre comparado a lixo, o lixo que carrega "bagaço, cascas de laranjas, de batata, de banana, uma embalagem vazia de macarrão e outra de salsicha, uma lacraia e cinco baratas, que ele acuou e esmagou no banheiro" (FIGUEIREDO , 2006, p. 81), mas também o saco de lixo que carrega mortos. Em um dia, quando Pedro jogou seu saco de lixo na caçamba, percebeu que "enquanto as moscas voavam para os lados, ele viu o saco de lixo bater e rolar sobre as costas de um homem morto, com as pernas dobradas e a cabeça enfiada em um saco de pano encharcada e vermelha" (FIGUEIREDO, 2006, p. 84).

Ao comprar a escrita de Inferno, de Patrícia Mello, com Cidade de Deus, Patrocínio assinala que "fica clara a opção de tratar a favela não apenas como um espaço da criminalidade, como optou Paulo Lins no romance Cidade de Deus, mas sim 
BARCELOS, Carolina Montebelo. Os diversos "Pedros" que habitam as cidades: violência e experiência urbana em "Contos de Pedro" e

"Passageiro do fim do dia", de Rubens Figueiredo. PragMATIZES

Revista Latino-Americana de Estudos em Cultura, Niterói/RJ, Ano 10, n. 18, p. 140-154, out. 2019 a março 2020.

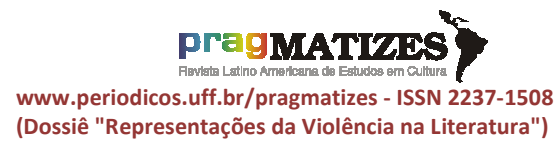

(Dossiê "Representações da Violência na Literatura") como um espaço de marginalidade, na qual a favela se constrói como um local posto à margem da cidade formal, mas nem tampouco independente". As situações narradas por Rubens Figueiredo se encontram mais próximas a essa ideia de "local posto à margem da cidade formal", mas que não estão independentes dela, já que seus personagens fazem parte de uma classe trabalhadora aviltada pela relação exploratória do trabalho realizado nessa cidade formal.

Beatriz Jaguaribe lê as diversas formas de representação atual da realidade através da expressão "pedagogia da realidade" e argumenta que

por "pedagogia da realidade" compreendo o uso de estéticas realistas em várias modalidades e expressões como meio de ilustrar retratos da realidade contemporânea de uma forma legível para espectadores ou leitores. Trata-se de uma pedagogia porque estes registros oferecem pautas interpretativas permeadas pelo sentido comum de problemas cotidianos compartilhados (JAGUARIBE, 2010, p. 7).

Essa compreensão de estética realista pode ser entendida na escrita de Rubens Figueiredo, uma vez que a realidade que ele se dispõe a retratar faz parte desses problemas cotidianos legíveis para os leitores. Ainda, segundo Jaguaribe, "[...] as estéticas realistas detêm forte poder de persuasão porque foram naturalizadas enquanto apreensões interpretativas da realidade social moderna" (JAGUARIBE, 2010, p. 7). Entretanto, na escrita de Rubens Figueiredo, não vemos um tratamento do realismo e uma busca da verossimilhança como ocorriam nos romances históricos do século XIX e apontados por Roland Barthes através do seu conceito de "efeito do real". Segundo Barthes, o "efeito do real"consistia nos elementos presentes no romance realista que, embora a princípio aparentassem irrelevância em relação ao que era narrado, eram de extrema importância para a leitura verossímil do romance. Entretanto, de acordo com Jaguaribe, "este 'efeito de realidade' contemporâneo não depende somente do detalhe verossímil, mas da força de intensificação da imagem que cria uma ilusão de realidade maior do que a nossa percepção amorfa do cotidiano" (JAGUARIBE, 2010, p. 8).

Enquanto a clara referência ao bairro Cidade de Deus, no Rio de Janeiro, conferia ao romance de Paulo Lins um caráter realista no sentido de 
tentar apreender o real tal como ele é, como um retrato da realidade, no romance e contos de Rubens Figueiredo, não há qualquer referência a cidades ou bairros conhecidos ou identificáveis. Em Passageiro do fim do dia, apesar das referências ao bairro Tirol, ao bairro "rival" Várzea e à praça da Bigorna, não há evidência alguma de que cidade se trata, apenas a certeza de Pedro de que Darwin esteve lá. Embora haja, no Rio de Janeiro, uma favela Tirol na Freguesia, Jacarepaguá, e Várzea, em Rocha Miranda, a curta distância que separa essas duas regiões, conforme diz o pai de Rosane na ida ao supermercado após a tia desta ganhar o cartão do governo, nos permite afirmar que não se trata, de fato, de Freguesia e Rocha Miranda. Pedro não conhece bem o Tirol e acha que quase ninguém conhece seu próprio bairro direito. Certamente se trata de um bairro periférico, empobrecido, semelhante às descrições de favelas cariocas. Dessa forma, o Tirol, assim como quase todos os bairros e cidades onde moram os Pedros dos contos, só existem enquanto ficção. Esse também é o recurso utilizado por Patrícia Mello em Inferno, já que a favela Berimbau, como aponta Paulo Roberto Tonani do Patrocínio "só existe enquanto romance" (PATROCÍNIO, 2006).

Ao se debruçar sobre a experiência urbana nos textos de Rubens Figueiredo, Tonani do Patrocínio nos lembra que o escritor "não dialoga apenas com a cidade real enquanto fonte de inspiração" (PATROCÍNIO, 2014, p. 96), como também "com os muitos discursos literários já existentes que representam a cidade" (PATROCÍNIO, 2014, p. 96). Tomando como aporte teórico as considerações de Beatriz Sarlo sobre uma certa predileção da ficção realista e naturalista sobre a temática e representação das cidades e de Flora Sussekind sobre não haver uma única naturalista no Brasil, mas reedições dela, Tonani do Patrocínio assevera que "o ciclo novamente se abre e o naturalismo, que antes parecia estar encapsulado na década de 1970, retorna agora com novas vestes e amparado em uma linguagem fria e direta que almeja representar a experiência urbana através do temário da violência”. (PATROCÍNIO, 2014, p. 99). 
BARCELOS, Carolina Montebelo. Os diversos "Pedros" que habitam as cidades: violência e experiência urbana em "Contos de Pedro" e

"Passageiro do fim do dia", de Rubens Figueiredo. PragMATIZES

Revista Latino-Americana de Estudos em Cultura, Niterói/RJ, Ano 10, n. 18, p. 140-154, out. 2019 a março 2020.

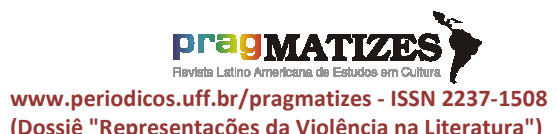

(Dossiê "Representações da Violência na Literatura")

\section{Considerações finais}

Pedro pedreiro penseiro esperando o trem Manhã, parece, carece de esperar também

Para o bem de quem tem bem De quem não tem vintém

Pedro pedreiro está esperando a morte

Ou esperando o dia de voltar pro norte

Pedro não sabe mas talvez no fundo

Espera alguma coisa mais linda que o mundo Maior do que o mar Mas pra que sonhar

Se dá o desespero de esperar demais

Pedro pedreiro quer voltar atrás

Quer ser pedreiro pobre e nada mais Sem ficar esperando, esperando, esperando

Chico Buarque, Pedro Pedreiro,1965

Assim como na "Lira Paulistana" a vida de Pedro é relatada por Mário de Andrade através da repetição, Chico Buarque também se vale desse recurso estilístico ao retratar a opressão da classe trabalhadora brasileira, na figura de Pedro Pedreiro. Os diversos Pedros que habitam o Passageiro do fim do dia e os Contos de Pedro perpassam os Pedros de Mário de Andrade e de Chico Buarque.

Conquanto o poema e a música tratam do indivíduo Pedro inserido em um contexto de opressão e desigualdade social, os Pedros de Rubens Figueiredo também experimentam a violência da área urbana e periférica, além da solidão. Ou como assinala Paulo Roberto
Tonani do Patrocínio, "tornar-se Pedro, uma rocha, nos parece ser uma saída possível para a busca por uma acomodação em uma cidade hostil e violenta" (PATROCÍNIO, 2016, p. 124).

Renato Cordeiro Gomes assinala que boa parte da escrita literária contemporânea procura se debruçar sobre "a experiência urbana dramatizada nas megalópoles em seus roteiros da violência, o espaço do medo e da invisibilidade, a solidão e a exclusão (não mais solidão-multidão)" (GOMES, 2007, p. 11). Não só tal assertiva diz respeito a Contos de Pedro, como essa observação pode ser estendida também a Passageiro do fim do dia e a toda obra de Rubens Figueiredo, embora, como nos mostra Beatriz Resende, "um dos raros momentos de esperança no destino humano, na possibilidade de se encontrar algum conforto ao lado de alguém, aparece onde menos se espera: na narrativa que Rubens Figueiredo constrói a partir, mais uma vez, em sua produção literária, do olhar do excluído" (RESENDE, 2002).

\section{Referências bibliográficas}

ANDRADE, Mário de. Lira paulistana. In: Poesias completas.Belo Horizonte: Itatiaia, 1987. Disponível em: 
BARCELOS, Carolina Montebelo. Os diversos "Pedros" que habitam as cidades: violência e experiência urbana em "Contos de Pedro" e

"Passageiro do fim do dia", de Rubens Figueiredo. PragMATIZES

Revista Latino-Americana de Estudos em Cultura, Niterói/RJ, Ano 10, n. 18, p. 140-154, out. 2019 a março 2020.

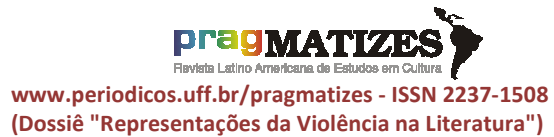

brasileiros. (Mestrado em Letras). Rio de Janeiro: PUC-Rio, 2006.

PATROCÍNIO, Paulo Roberto Tonani do. Os (não) adaptados: a experiência urbana na obra de Rubens Figueiredo. In: RESENDE, Beatriz (org.). Possibilidades da nova escrita literária no Brasil. Rio de Janeiro: Revan, 2014. p. 91-107.

PATROCÍNIO, Paulo Roberto Tonani do. Passageiro do fim do dia, de Rubens Figueiredo: um olhar sobre o naturalismo. In: CHIARELLI, Stefania; DEALTRY, Giovanna; VIDAL, Paloma (orgs.). $O$ futuro pelo retrovisor. inquietudes da literatura brasileira contemporânea. Rio de Janeiro: Rocco, 2013. p. 261-278.

RESENDE, Beatriz. Contemporâneos: expressões da literatura brasileira no século XXI. Rio de Janeiro: Casa da Palavra, 2008.

RESENDE, Beatriz. Ficção brasileira hoje: a multiplicidade como sintoma. In: Semear. Revista da Cátedra Padre Antonio Vieira de Estudos Portugueses. Rio de Janeiro, PUC-Rio, n. 7, 2002. Disponível em: http://www.letras.puc-

rio.br/unidades\&nucleos/catedra/revist a/7Sem_13.html. Acesso: 9 dez. 2019.

SCHOLLHAMMER, Karl Erik. Ficção brasileira contemporânea. Rio de Janeiro: Civilização Brasileira, 2009. dagogias do olhar na América Latina contemporânea.Ciberlegenda, Niterói, no 23, 2으, p. 6-14, 2010.

PATROCÍNIO, Paulo Roberto Tonani do. Cidade de lobos: a representação de territórios marginais na obra de Rubens Figueiredo. Belo Horizonte: Editora UFMG, 2016.

PATROCÍNIO, Paulo Roberto Tonani do. Entre o morro e o asfalto: imagens da favela nos discursos culturais 